\title{
Evolutionary consequences of shifts to bird-pollination in the Australian pea-flowered legumes (Mirbelieae and Bossiaeeae)
}

\author{
Alicia Toon ${ }^{1,2^{*}}$, Lyn G Cook and Michael D Crisp ${ }^{2}$
}

\begin{abstract}
Background: Interactions with pollinators are proposed to be one of the major drivers of diversity in angiosperms. Specialised interactions with pollinators can lead to specialised floral traits, which collectively are known as a pollination syndrome. While it is thought that specialisation to a pollinator can lead to either an increase in diversity or in some cases a dead end, it is not well understood how transitions among specialised pollinators contribute to changes in diversity. Here, we use evolutionary trait reconstruction of bee-pollination and bird-pollination syndromes in Australian egg-and-bacon peas (Mirbelieae and Bossiaeeae) to test whether transitions between pollination syndromes is correlated with changes in species diversity. We also test for directionality in transitions that might be caused by selection by pollinators or by an evolutionary ratchet in which reversals to the original pollination syndrome are not possible.

Results: Trait reconstructions of Australian egg-and-bacon peas suggest that bee-pollination syndrome is the ancestral form and that there has been replicated evolution of bird-pollination syndromes. Reconstructions indicate potential reversals from bird- to bee-pollination syndromes but this is not consistent with morphology. Species diversity of bird-pollination syndrome clades is lower than that of their bee-pollination syndrome sisters.

We estimated the earliest transitions from bee- to bird-pollination syndrome occurred between $30.8 \mathrm{Ma}$ and 10.4 Ma. Geographical structuring of pollination syndromes was found; there were fewer bird-pollination species in the Australian southeast temperate region compared to other regions of Australia.

Conclusions: A consistent decrease in diversification rate coincident with switches to bird pollination might be explained if greater dispersal by bird pollinators results in higher levels of connectivity among populations and reduced chances of allopatric speciation.

The earliest transitions overlap with the early diversification of Australian honeyeaters - the major lineage of pollinating birds in Australia. Our findings are consistent with the idea that environment and availability of pollinators are important in the evolution of pollination syndromes. Changes in flower traits as a result of transitions to bird-pollination syndrome might also limit reversals to a bee-pollination syndrome.
\end{abstract}

Keywords: Pollination syndrome, Adaptive radiation, Ancestral state reconstruction, Diversification

\footnotetext{
*Correspondence: a.toon@uq.edu.au

${ }^{1}$ The University of Queensland, School of Biological Sciences, Brisbane Qld 4072, Australia

${ }^{2}$ Research School of Biology, The Australian National University, Canberra ACT 0200, Australia
}

\section{Biomed Central}

(c) 2014 Toon et al.; licensee BioMed Central Ltd. This is an Open Access article distributed under the terms of the Creative Commons Attribution License (http://creativecommons.org/licenses/by/2.0), which permits unrestricted use, distribution, and reproduction in any medium, provided the original work is properly credited. The Creative Commons Public Domain Dedication waiver (http://creativecommons.org/publicdomain/zero/1.0/) applies to the data made available in this article, unless otherwise stated. 


\section{Background}

The extraordinary radiation of flowering plants (angiosperms) accounts for about $91 \%$ of all plant species and forms the foundations of terrestrial biodiversity $[1,2]$. This expansive evolution of species and morphological diversity has been attributed, at least in part, to interactions with animals $[3,4]$ - particularly changes in specialist pollinators that might drive diversification [5-7]. There is good evidence that shifts between specialized pollinators are correlated with increased diversification in some angiosperm groups and decreases in others [8,9].

The vast majority of flowering plants are pollinated by animals [10], including insects, birds, bats and other vertebrates, and there is good evidence that preferences of pollinators for different flower forms can lead to reproductive isolation in plants [11]. When interactions are specialized, the plant typically exhibits a pollination syndrome - a suite of floral characteristics that attract and provide food resources for a particular pollinator or pollinator guild [12,13]. For example, a bird-pollination syndrome typically involves large, red, tubular flowers, copious nectar and sexual parts positioned to deposit pollen on the bird (Figure 1). In contrast, bee-pollination syndromes have predominantly yellow, white or blue flowers (most hymenopteran pollinators have difficulty in discerning red flowers with a reflectance spectrum above $585 \mathrm{~nm}$ because they will not stand out from the green foliage $[14,15])$, a landing platform and guide marks and nutrient-rich nectar (Figure 1).

It has been shown that pollination syndromes are integrated and are subject to selection that limits divergence in particular component traits away from some optimum (stabilizing selection, e.g., Figure 2) [17]. Nevertheless, there appear to have been many transitions between specialised pollination syndromes during the diversification of the angiosperms [18-20] but it appears that not all transitions are equally likely. Directional bias in transitions between specialised pollination syndromes, e.g., from bee-pollination to bird-pollination, has been indicated in several studies [18-20]. Such a bias could be caused by a structuralfunctional constraint preventing reversal of the complex trait of bird-pollination syndrome to a bee-pollination syndrome (an evolutionary 'ratchet mechanism' that facilitates transitions in one direction, $[18,19]$ ). For example, a flower specialised for bird pollination could be so large, with sexual parts so well separated, that a small insect (such as a small bee) could not effectively transfer pollen and thus would not exert disruptive selection on floral traits [19]. Similarly, it has been suggested that nectar in Aquilegia with floral spurs adapted to long-tongued pollinators (hummingbirds or hawkmoths) is inaccessible to short-tongued bees, which therefore do not exert selection on spur length [18]. A directional bias could also reflect a historical change in abundance of pollinator guilds, e.g., nectar-feeding birds
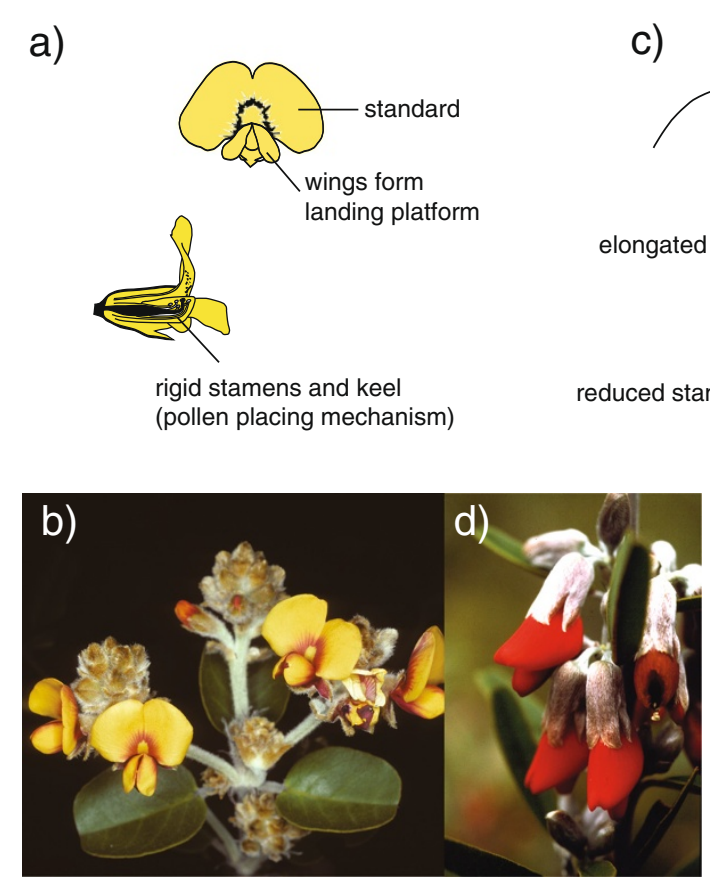

c)

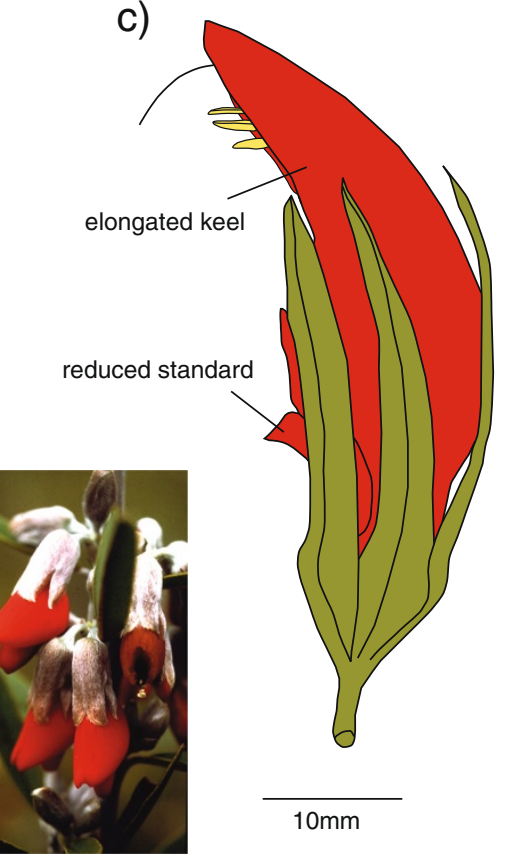

Figure 1 Pollination syndromes. Bee-pollination syndrome: a) Dillwynia uncinata, showing the wing and keel that together act as a trigger mechanism. When a bee pushes down on the wings of a pea flower, the wings separate and trigger the sexual parts to rise out of the keel and deposit pollen from the anthers onto the bee. b) Flowers of Gastrolobium pyramidale. Bird-pollination syndrome: c) Leptosema aphyllum, showing the resupinate orientation and large size. d) Flowers of Gastrolobium rubrum. Figure a) adapted from Gross [16]. 

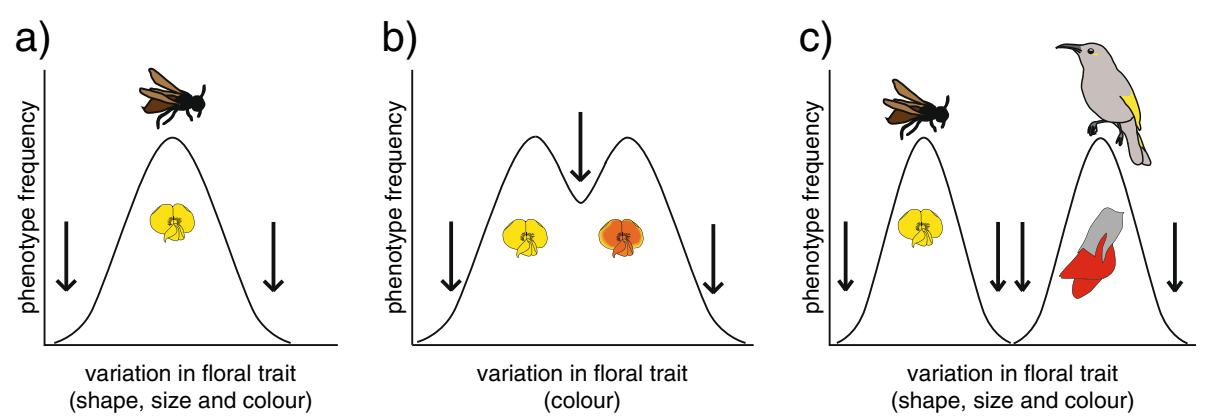

Figure 2 Selection on flower colour and shape exerted by pollinators. Example of how discrimination on floral traits by pollinators can limit divergence away from a pollination syndrome through stabilising selection or promote divergence towards a new pollination syndrome. Distributions represent the frequency of phenotypic variation within syndromes and arrows show phenotypes selected against by pollinators. Bee pollinators select for a) yellow flower colour, open shape and small size, limiting divergence away from the bee-pollination syndrome. b) An increase in pollination by birds in part of the species range might promote divergence in floral traits by selecting for flowers with a greater proportion of red (preferred by birds and less attractive to bees), followed by c) selection for larger size and pendular orientation.

might have evolved later than pollinating bees, or geographical variation in the distribution of pollinators caused by environmental heterogeneity, e.g., climatic factors that vary with altitude [21].

The legume tribes Mirbelieae and Bossiaeeae (the Australian "egg-and-bacon" peas) are a good system for addressing questions about floral transitions. Together, they comprise a diverse endemic Australian lineage in which species are specialised for either bee or bird pollination (Figure 1), as indicated both by direct observation [22-26] and by morphological syndromes [27,28]. Here we use comparative analyses of dated molecular phylogenies to address two questions:

1. Is pollination syndrome correlated with species diversity? If pollinators are influencing angiosperm diversification, there might be observable differences in diversity after shifts in pollinator.

2. Are all shifts equally likely? It would be expected that, if pollinator use is correlated with environment or if there is an evolutionary ratchet mechanism, there would be asymmetry in the directions of pollinator shifts.

\section{Methods}

We sampled about half of the 700 known species of Mirbelieae and Bossiaeeae (Fabaceae, Australian egg-and-bacon peas), which are comprised of major endemic Australian pea genera such as Daviesia, Bossiaea, Pultenaea, Mirbelia and Gastrolobium. Trees were rooted with outgroups that included the likely sister group (Hypocalyptus), and other taxa sampled from across the legumes using Wojciechowski et al. (2004) [29] as a guide to relationships. Sequences of two cpDNA loci ( $n d h F$ and $\operatorname{trnL-trnF)}$ and one nrDNA locus (ITS1, 5.8S and ITS2) were obtained from our previous studies ([30] and references cited therein). DNA sequences were edited using Sequencher v4.5
(GeneCodes) and aligned manually in Se-Al v2.0a11 [31]. Parts of the ITS and trnL-trnF sequences that were not confidently aligned across the more distantly related terminals were offset or omitted. Ambiguity in aligning trnL-trnF and ITS prevented the use of outgroups more distantly related than Baphia.

\section{Phylogenetic analysis}

Phylogenies were estimated for each locus using maximum likelihood (ML) in GARLI v0.951 [32] and a Bayesian MCMC search using MrBayes v3.1.2 [33]. All phylogenetic analyses incorporated a GTR + I + G model. As the resulting topologies and branch lengths showed little difference between the two search methods, all subsequent analyses used the GARLI trees with the best likelihood scores. The

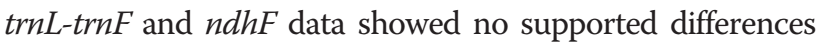
in resolution and were combined into a single cpDNA partition for comparative analyses. Other specifics of analyses were as per Crisp and Cook [30].

Phylograms were transformed into chronograms, in which branch lengths were proportional to time, using penalized likelihood (PL) in r8s v1.71 [34] with smoothing parameters optimised by fossil-based cross validation. To estimate ages of nodes, several primary (fossil-based) and secondary calibration points were used, as described previously [30]. We used the dated phylogenies to infer the timing of the earliest transitions between pollination syndromes. Confidence intervals around stem nodes of birdpollination syndrome clades (crown node ages represent the latest possible transition time) were estimated from the ITS data and from the combined cpDNA data using 100 ML bootstrap trees with the 'profile' function in r8s.

\section{Transitions between pollination syndromes}

Ancestral states for the root and internal nodes were inferred from each phylogeny using parsimony-based models as implemented in Mesquite version 2.74 [35]: 
equal-weighted parsimony and Dollo parsimony (bird, once gained from bee, is irreversible). The "Dollo" model is based on the arguments that, once lost, a complex trait cannot revert to exactly the same form it was before the change $[36,37]$. Pollination syndrome may satisfy the criterion of a complex trait because flowers of different syndromes differ in multiple, integrative floral attributes, including colour, shape, nectar and orientation [12]. If evolution of floral morphology underlying a birdpollination syndrome involves changes in multiple pathways, it might be expected that changes back to a bee-pollination syndrome might be difficult or, if it does occur, results in a morphology that is somewhat different from the ancestral bee-pollinated floral morphology.

\section{Differences in diversity}

If shifts in pollination syndrome have contributed to the diversity of angiosperms, we might expect there to be observable differences in species diversity of clades exhibiting different pollination syndromes. Sister-clade comparisons are a good way of testing for species-richness differences if a sufficient number of pairs are available to provide power to the test. Sister clades share a single common ancestor and so any differences in species diversity must have arisen since their divergence from that ancestor. We tested whether there was a difference in species richness between clades with bird- and bee-pollination syndrome using a Wilcoxon signed-rank test of sister clades as implemented in GraphPad Prism 5.03, GraphPad Software, San Diego California USA, www.graphpad.com. Given that there were slight differences in topologies among trees derived from the different DNA regions, we conducted the sister-taxon comparisons separately using ML trees from both ITS and combined cpDNA. One sister pair of bird-bee-pollination syndrome was removed from the ITS analysis because of uncertain phylogenetic resolution. There was insufficient phylogenetic resolution to identify the sister to the birdpollination syndrome clade (i.e., it was part of a polytomy) in Gastrolobium in both gene trees, so we combined the unresolved bee-pollination syndrome species into a single clade. Combining these clades did not bias the result because the total species diversity of the combined beepollination syndrome clades was less than that of the birdpollination syndrome clade - our approach was conservative. To complement the sister-pair comparisons, we used the BiSSE approach [38] available in Mesquite v2.74 (with the Goldberg correction module, [39]) to test the null hypothesis that diversification rates remained constant through inferred transition events, i.e., that there was no difference in diversification rates of bee- and bird-pollination syndrome clades. We compared the models using Akaike information criterion (AIC) following Burnham [40], where the model with the lower score is a better fit.

\section{Geographic distribution of pollination syndromes}

If different pollination syndromes are favoured under different ecological conditions, we might expect them to be represented differently in each major habitat. We tested whether there was geographic variation in the proportion of bird- and bee-pollination syndrome species richness as a proxy for an external ecological driver. We categorised all described species of Mirbelieae and Bossiaeeae as occurring in one or more of four biomes based on distribution data from Australia's Virtual Herbarium (http://chah.gov.au/avh/index.jsp, accessed 11 Nov 2011) and regions described in [41,42]: southeast temperate, southwest temperate, central (arid), and tropical (monsoon tropics). We used a Chi-squared test to determine whether there was a difference in the proportion of bird-pollination syndrome species occurring in these regions.

\section{Results}

A bee-pollination syndrome is clearly reconstructed as ancestral in the Australian egg-and-bacon peas (Figures 3 and 4, Additional file 1: Figure S1 and Additional file 2: Figure S2). In all analyses, species with a bird-pollination syndrome are nested within clades of bee-pollinated taxa that are well supported by posterior probability (Bayesian) and bootstrap support (maximum likelihood) (Additional file 1: Figure S1 and Additional file 2: Figure S2). The earliest transition to bird-pollination syndrome was reconstructed on the stem leading to the Leptosema clade. We estimated the earliest transition occurred between $25.7 \mathrm{Ma}(95 \% \mathrm{CI}=20.6-30.8 \mathrm{Ma}$; stem age) and 16.8 Ma (95\% CI =10.4-23.2 Ma; crown age) using cpDNA data and 23.6 Ma (95\% CI $=16.8-29.6 \mathrm{Ma}$; stem age) and 13.4 Ma (95\% CI = 7.6-19.2 Ma; crown age) using ITS data.

\section{Diversity}

We compared diversity of sister clades differing in pollination syndrome and found that clades of species with birdpollination syndrome had fewer species than their sister clade with bee-pollination syndrome (Wilcoxon signedrank tests: combined cpDNA: $\mathrm{n}=11, \mathrm{Z}=-2.073, P=0.038$; ITS: $\mathrm{n}=11, \mathrm{Z}=-2.014, P=0.044)$. The BiSSE model, which accounts for interaction between trait states and diversification rates, marginally supported the state-independent maximum likelihood (ML) models over state-dependent models (delta AIC = 3.96), although both models are still favoured where delta $\mathrm{AIC}<4[40]$.

\section{Shifts in pollination syndrome}

Phylogenetic relationships in the egg-and-bacon peas differed between estimates using cpDNA and ITS, resulting in slightly different reconstructions of transitions between bee- and bird-pollination syndromes 


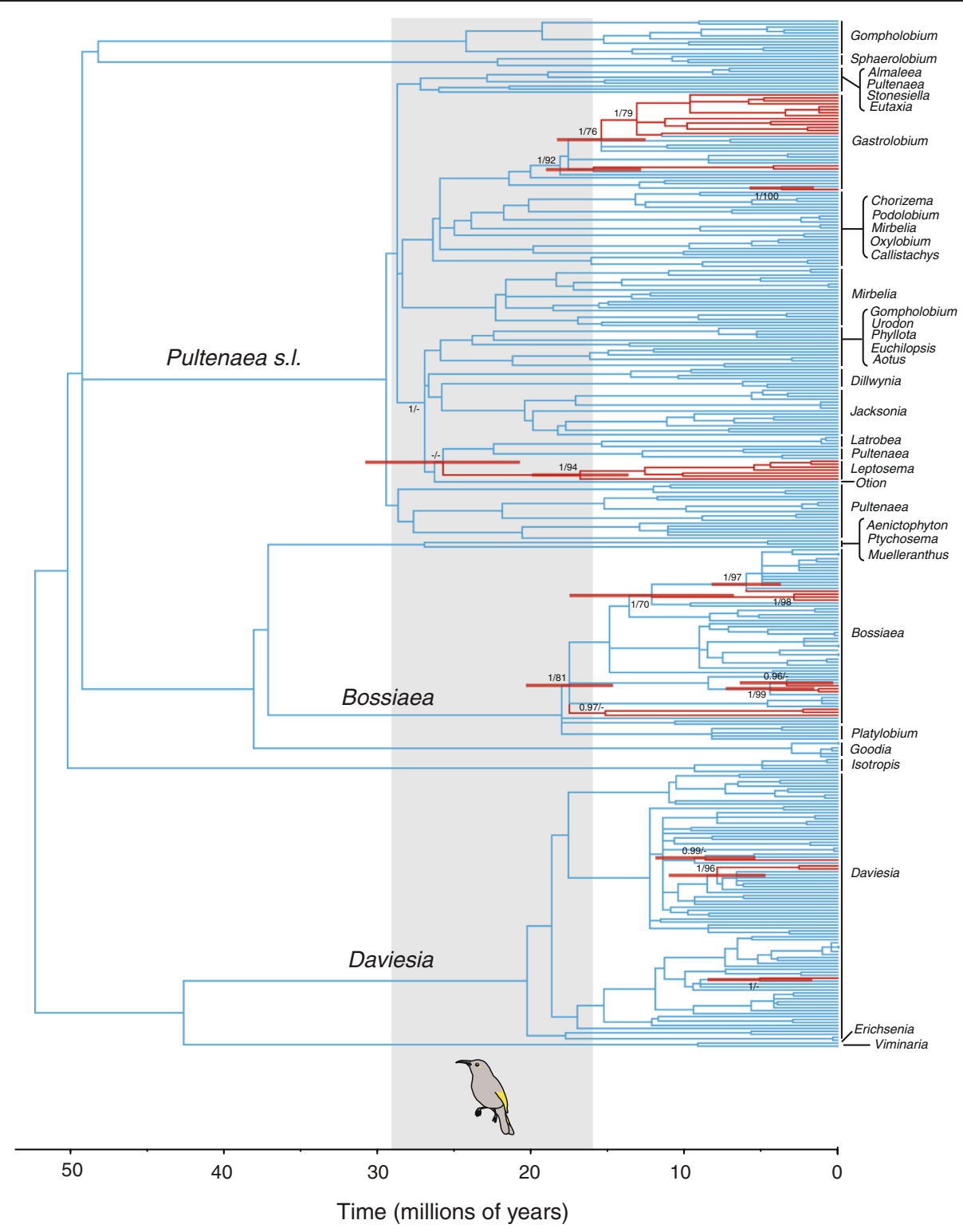

Figure 3 Dating origins of bee- and bird-pollination syndromes using cpDNA. Chronogram of Mirbelieae and Bossiaeeae derived from Maximum Likelihood analysis of combined cpDNA sequence data using PL rate smoothing. Parsimony trait reconstruction of bee- (blue) and bird- (red) pollination syndromes (no directional weighting) is shown on tree. Red bars show 95\% confidence intervals of stem age of bird-pollination syndrome transitions and crown age of the earliest inferred bird-pollination syndrome transition (Leptosema). Posterior probabilities $>0.95$ ( $P$ P) and bootstrap support > 70 (BS) are shown on stem and crown nodes of bird-pollination syndrome transitions. Where node support is lower than $0.95 / 70, P P$ and $B S$ is also shown on the node above the transition. Inferred crown and stem age (95\% highest probability density) of honeyeaters (Meliphagidae) is shaded grey.

(Additional file 1: Figure S1 and Additional file 2: Figure S2). This uncertainty in reconstructing shifts of pollinator syndrome is centred around relationships within Gastrolobium, many of which do not have strong support (Additional file 1: Figure S1 and Additional file 2: Figure S2). The single inferred reversal in analyses of cpDNA involved a transition back to bee-pollination syndrome in G. pyramidale (Figure 5), but this node is not well supported and the alternative resolution, in which G. pyramidale is sister to a clade of bird-pollination syndrome species instead of within the clade, is not rejected. The five or six reversals inferred in ITS analyses are also within Gastrolobium and do not have strong support (Additional file 1: Figure S1 and Additional file 2: Figure S2). For example, G. alternifolium is placed with two bird-pollination syndrome species $(P P=0.96)$ but their position among other bird-pollinated species 


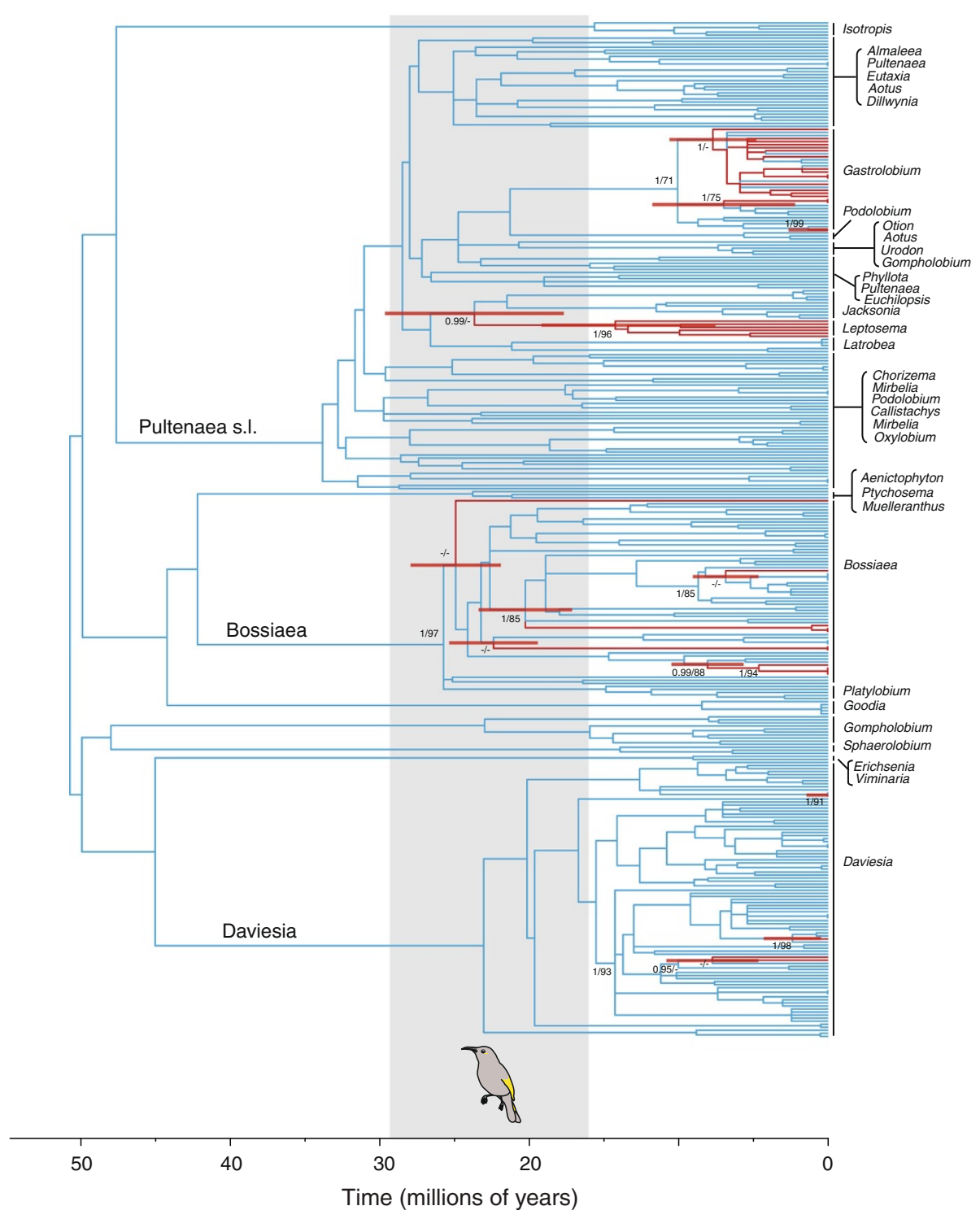

Figure 4 Dating of origins of bee- and bird-pollination syndromes using ITS. Chronogram of Mirbelieae and Bossiaeeae derived from Maximum Likelihood analysis of ITS sequence data using PL rate smoothing. Parsimony trait reconstruction of bee- (blue) and bird- (red) pollination syndromes (no directional weighting) is shown on tree. Red bars show $95 \%$ confidence intervals of stem age of bird-pollination syndrome transitions and crown age of the earliest inferred bird-pollination syndrome transition (Leptosema). Posterior probabilities $>0.95$ (PP) and bootstrap support $>70(\mathrm{BS})$ are shown on stem and crown nodes of bird-pollination syndrome transitions. Where node support is lower than $0.95 / 70, P P$ and $B S$ is also shown on the node above the transition. Inferred crown and stem age ( $95 \%$ highest probability density) of honeyeaters (Meliphagidae) is shaded grey.

has low resolution and in the cpDNA analysis, G. alternifolium is placed with bee-pollination syndrome species (Additional file 1: Figure S1 and Additional file 2: Figure S2).

In all reconstructions, there were many more inferred shifts from bee- to bird-pollination syndrome than the reverse (Table 1). An assumption of no reversals from bird- to bee- pollination syndrome (Dollo's law) resulted in one extra transition (14 vs 13) in analyses of cpDNA, and two extra transitions (20 vs 18 ) in analyses of ITS (Table 1).

\section{Geographic distribution of pollination syndromes}

There are proportionally fewer bird-pollination syndrome species of egg-and-bacon peas in the Australian southeast temperate region (SET) (about $1 \%$ ) than any other region (Chi-squared $=15.108$, $\mathrm{df}=3, \quad P=0.0017)$, and no significant difference 


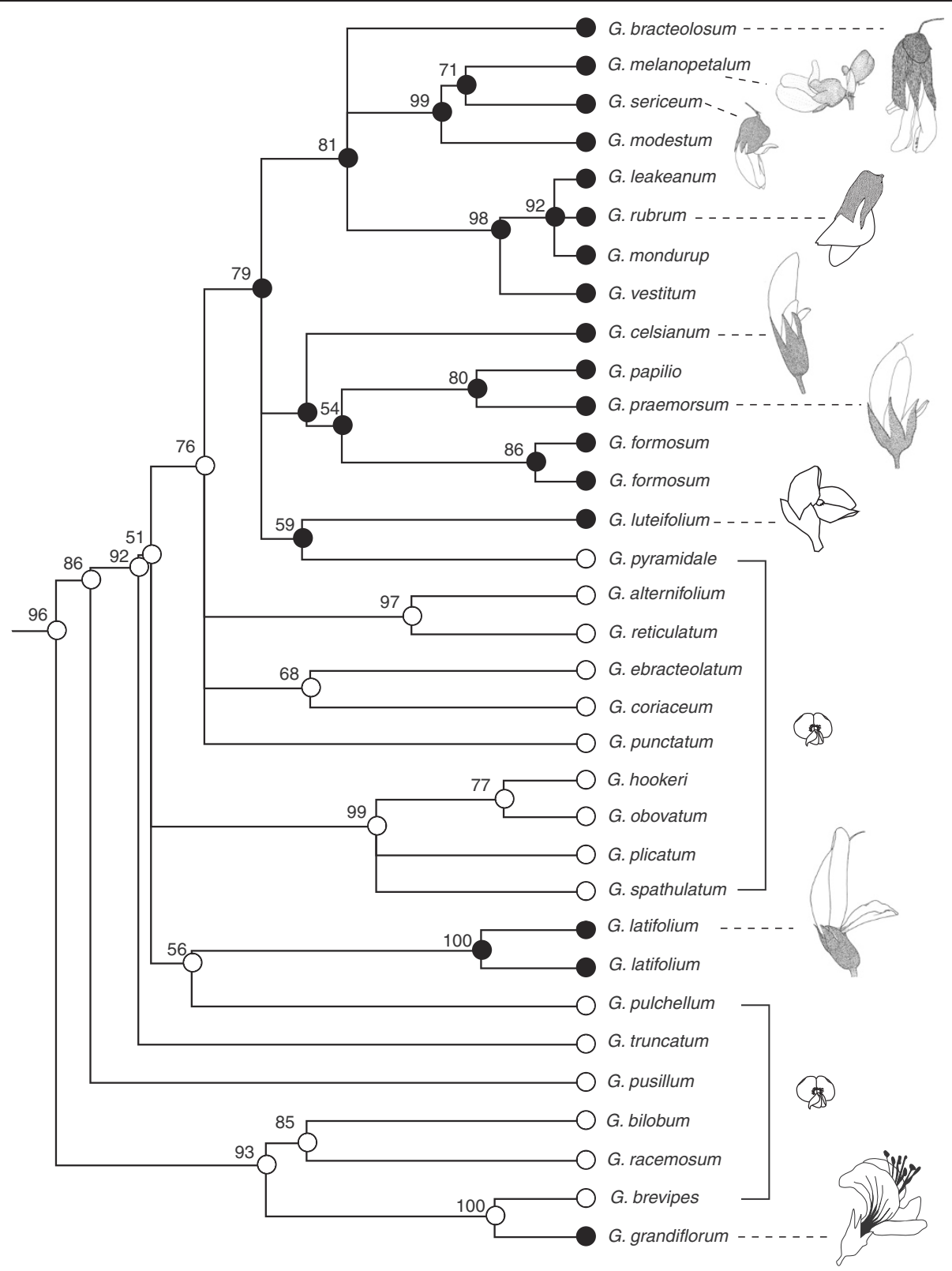

Figure 5 Pollination syndrome in Gastrolobium. Maximum likelihood tree of combined cpDNA sequences showing relationships among Gastrolobium species and inferred bee- and bird-pollination syndromes. Parsimony ancestral reconstruction of bee-pollination syndrome (white circles) and bird-pollination syndrome (black circles) is shown on the nodes. Bootstrap support is shown on the branches. Examples of flowers highlight the diversity in shape of the bird-pollination syndrome flowers.

Table 1 Number of transitions between bee- and bird-pollination syndromes inferred from maximum parsimony (MP) reconstruction methods using the ITS and cpDNA phylogeny

\begin{tabular}{lllll}
\hline Dataset & Model & Bee to bird & Bird to bee (reversals) & Total transitions \\
\hline ITS chronogram & MP (equal weighted) - MPR1 & 12 & 6 & 18 \\
& MP (equal weighted) - MPR2 & 11 & 7 & 18 \\
& Dollo parsimony & 20 & 0 & 20 \\
cPDNA chronogram & MP (equal weighted) & 12 & 1 & 13 \\
& Dollo parsimony & 14 & 0 & 14 \\
\hline
\end{tabular}


between proportions in the southwest temperate (5.9\%), tropical $(9.3 \%)$ and central $(10.5 \%)$ regions (Chi-squared $=$ $2.781, \mathrm{df}=2, P=0.249$ ).

\section{Discussion}

Pea flowers of the subfamily of legumes classified as Faboideae (or Papilionoideae) arose about $58 \mathrm{Ma}$ [43] and are thought to have evolved as a specialisation to pollination by bees [44]. Our reconstruction of a bee-pollination syndrome as ancestral for the Australian egg-and-bacon peas is consistent with it being the ancestral syndrome for the entire subfamily. The main bird pollinators of Australian egg-and-bacon peas, the honeyeaters (Meliphagidae), probably radiated between 15.9-29.4 Ma [45]. The earliest transitions to bird-pollination syndrome, which we estimated to have occurred ca. 10.4-30.8 Ma (cpDNA) and 7.6-29.6 Ma (ITS), mostly overlap with the radiation of honeyeaters. Thus, our results are consistent with this pollination syndrome being dependent on the availability of potential pollinators: bees of several families were present in Australia before the diversification of honeyeaters (e.g., [46,47]), and it appears that egg-and-bacon peas only switched to birdpollination syndromes once the honeyeaters were present to exert selection pressure on flower morphology. The honeyeaters have a visual system that responds well to the red wavelengths [48], and multiple lineages of Australian plants, such as Proteaceae [49], appear to have developed floral syndromes that are coloured for the tetrachromic vision of honeyeaters after this group radiated [50].

Similarly to reports for some plants outside Australia (e.g., [51,52]), we found that lineages of the Australian eggand-bacon peas exhibiting a bird-pollination syndrome have fewer species than their sister clades of bee-pollination syndrome species. Differences in species diversity are explained by changes in diversification rate, that is, in the rates of speciation and/or extinction. Pollination syndromes could directly influence either rate (speciation or extinction) by affecting genetic connectivity across a species' range over time [53]. Different pollinators move pollen across different distances, thus affecting genetic connectivity across a species range (eg., $[54,55])$. Australian honeyeaters have been found to distribute pollen over distances of $10^{3}-10^{4}$ metres whereas bees typically do so over $10^{2}$ metres [56-58], and bees transfer pollen between flowers less efficiently than birds [19]. Lower levels of pollen movement could lead to greater spatial genetic structure and increase the chance of speciation via allopatric speciation in beepollinated taxa compared to bird-pollinated taxa. The corollary of this is that bird-pollinated taxa should be subject to lower levels of differentiation in allopatry.

\section{Directional bias in transitions in pollination syndrome}

We found multiple independent origins (replicated evolution) of bird-pollination syndromes within the Australian egg-and-bacon peas with few, if any, reversals back to a bee-pollination syndrome. This asymmetry in direction of pollinator transitions might have several underlying causes.

1. The floral morphology that suits pollination by birds might have resulted in sexual parts oriented in such a way that bees do not transfer pollen between flowers, and thus do not exert selection pressure on birdpollination syndrome flowers. That is, the system represents an evolutionary ratchet mechanism where, once floral morphology has diverged sufficiently, reversions to the previous state are rare.

Although all reconstructions favoured at least one reversal from bird-pollination syndrome to bee-pollination syndrome, a Dollo model (no reversals) required only one or two additional switches in pollination syndrome (Table 1). Determining which reconstruction is most accurate cannot be determined from phylogenies alone (e.g., $[59,60])$ and additional information is required to test hypothesised pathways. Under a scenario of replicated evolution of a trait (here bird-pollination syndrome) it is expected that, in most cases, the trait will have evolved in slightly different ways because the lineages are independent, although they might be closely related. This is evident in parallel transitions to bird-pollination syndrome in egg-and-bacon peas. There are some commonalities, such as enlarged and/or red tubular corollas, but there are also lineage-specific differences, as expected. For example, G. rubrum and G. bracteolosum have a reduced standard, enlarged keel and are pendulous, whereas some others (G. leakeanum, G. mondurup and G. vestitum) have a flower shape more similar to a typical beepollination syndrome but are resupinate (turned upside down) and much larger (Figure 5). Others, such as G. melanopetalum, G. sericeum and G. modestum, have cream or black flowers that are inflated at the base, with a small keel and canaliculate (longitudinally grooved) standard.

Similarly, and as stated under Dollo's model, if a complex trait is lost it is unlikely to re-evolve in exactly the same form. For example, some flowers that appear to have undergone reversals from zygomorphy (monosymmetry) to ancestral polysymmetry have been found to have vestiges of their zygomorphic past (e.g., asymmetrical stamen development in Saintpaulia) or a different form of polysymmetry (e.g., six petals instead of five) [61]. In all our analyses, G. pyramidale (bee-pollination syndrome) was reconstructed as having been derived from a lineage that exhibited bird-pollination syndromes. However, we do not think reversal is the best explanation. Firstly, the node was only weakly supported by either DNA region and it is possible that this taxon is sister to the bird-pollination syndrome clade rather than being derived from within it. Secondly, even if the topology is accurate, G. pyramidale has a floral morphology that is indistinguishable from other bee-pollination syndrome taxa in Gastrolobium - it looks the same as a 
typical bee-pollination syndrome member of the eggand-bacon peas. Other species of Gastrolobium (e.g., G. alternifolium) that were inferred as a reversal of birdpollination syndrome to bee-pollination syndrome also look the same as a typical bee-pollination syndrome. We think it is more likely that there have been more transitions to bird-pollination syndrome in this lineage, consistent with the Dollo model and the observation of multiple different forms of bird-pollination syndrome in the clade, and that G. pyramidale has not changed from its bee-pollination syndrome ancestry.

2. An alternative explanation to the bias in direction of pollination syndrome transitions might be that current environmental conditions favour bird pollination over bee pollination, and thus there is little selection favouring reversals. Orians and Milewski [62] postulated that Australia has more vertebrate-pollinated species than other continents because it has poor soils and ample sunshine. Under such conditions and with sufficient water, plants are able to produce excess carbohydrates and thus make copious quantities of nectar, which attracts large vertebrates [63]. The nectar produced on nutrient poor soil might be low in proteins [63], however, unlike insect-pollinators, vertebrates readily acquire proteins from other sources in their diet such as insects [62]. Our findings are partly consistent with this idea because we found greater proportions of bird-pollination syndrome egg-and-bacon peas in regions with poorest soils (southwest temperate, central and tropical Australia) compared with the more fertile southeast temperate region. However, the ability to make copious nectar cannot explain the transition to a bird-pollination syndrome, only that it is possible. Other ecological factors that favour bird over bee pollination must be present. For example, differences in abundance of pollinators across the landscape might drive the initial divergence needed for speciation [5,6], and classic studies on Mimulus [21] support this as a likely mechanism. Most Australian honeyeaters feed also on insects and are not limited to nectar [64], so they can persist in areas and through seasons when bees are absent. Pollinator abundance might also be influenced by the presence of other species of flowering plants. Coexistence of peas in a community with a high abundance of bird-pollinated taxa, such as in southwest Western Australia [25], might promote reproductive success in peas that switch to bird-pollination by increasing visitation of pollinators and providing shelter and nesting for birds, as suggested for banksias and eucalypts by He et al. [65].

\section{Conclusions}

The Australian egg-and-bacon peas exhibit replicated evolution of bird-pollination syndromes, with little evidence that there have been switches back to an ancestral-type bee-pollination syndrome. Our reconstructions inferred that a shift in pollinator has repeatedly led to a decrease in diversification rate, with bird-pollination syndrome clades less species rich than their bee-pollination syndrome sisters. This might be explained if greater dispersal of birdpollinators results in higher levels of connectivity and decreases the chance of allopatric speciation in birdpollinated species. Further studies comparing gene flow and population structure will contribute towards an understanding of how different pollination specialisations have contributed to the diversification of angiosperms.

\section{Availability of supporting data}

Additional file 1: Figure S1.

Additional file 2: Figure S2.

\section{Additional files}

\begin{abstract}
Additional file 1: Figure S1. Bayesian estimate of Mirbelieae and Bossiaeeae phylogeny using combined cpDNA sequence data showing clades that include both bird (red) and bee (black) pollinator syndromes. Full tree is shown on left with partial tree (bold in full tree) on right of a: Gastrolobium, b: Bossiaea and Platylobium, c: Daviesia and d: Gompholobium, Urodon, Aotus, Euchilopsis, Phyllota, Dillwynia, Jacksonia, Leatrobea, Pultenaea and Leptosema. Posterior probabilities (PP > 0.95) from Bayesian analysis and bootstrap support of bipartitions (BS > 0.70) from maximum likelihood analysis are shown on branches. Scale bar represents substitutions per site.

Additional file 2: Figure S2. Bayesian estimate of Mirbelieae and Bossiaeeae phylogeny using ITS sequence data showing clades that include both bird (red) and bee (black) pollinator syndromes. Full tree is shown on left with partial tree (bold in full tree) on right of a: Gastrolobium, b: Bossiaea and Platylobium, c: Daviesia and d: Jacksonia and Leptosema. Posterior probabilities $(P P>0.95)$ from Bayesian analysis and bootstrap support of bipartitions $(B S>0.70)$ from maximum likelihood analysis are shown on branches. Scale bar represents substitutions per site.
\end{abstract}

\section{Abbreviation}

ML: Maximum likelihood; PL: Penalized likelihood; AIC: Akaike information criterion; PP: Posterior probabilities; BS: Bootstrap support; MP: Maximum parsimony; SET: Southeast temperate region; SWT: Southwest temperate region.

\section{Competing interests}

The authors declare that they have no competing interests.

\section{Authors' contributions}

AT analysed the data and led preparation of the manuscript. LGC conceptualized the project and collected data. MDC conceptualized the project, collected and analysed data. All authors contributed to writing of the manuscript and read and approved the final manuscript.

\section{Acknowledgements}

We thank David Morris for some DNA sequencing and Emma Goldberg for supplying a script for setting root states in Mesquite. Funding was provided by the Australian Research Council (grant number: DP0985473). We thank the Papers in the Pub and Coopers \& Cladistics discussion groups and the Cook and Crisp lab groups, for valuable discussion on ancestral state reconstruction and modelling of tree.

Received: 6 September 2013 Accepted: 19 February 2014 Published: 7 March 2014 


\section{References}

1. Paton AJ, Brummitt N, Govaerts R, Harman K, Hinchcliffe S, Allkin B, Lughadha EN: Towards target 1 of the global strategy for plant conservation: a working list of all known plant species-progress and prospects. Taxon 2008, 57(4):1371-1371.

2. The plant list. In Vol. Version 1; 2010. http://www.theplantlist.org/ (accessed 2nd May 2013).

3. Crepet WL, Niklas KJ: Darwin's second "abominable mystery": why are there so many angiosperm species? Am J Bot 2009, 96(1):366-381.

4. de Saporta G, Marion AF: L'évolution du règne végétal. Les Phanérogames. Saint Germain, France: Ancienne Librairie Germer Baillière; 1885.

5. Grant V: Pollination systems as isolating mechanisms in angiosperms. Evolution 1949, 3(1):82-97.

6. Stebbins GL: Adaptive radiation of reproductive characteristics in angiosperms. I. Pollination mechanisms. Annu Rev Ecol Syst 1970, 1:307-326.

7. Johnson SD: The pollination niche and its role in the diversification and maintenance of the southern African flora. Philos Trans R Soc Lond B Biol Sci 2010, 365(1539):499-516.

8. Kay KM, Sargent RD: The role of animal pollination in plant speciation: integrating ecology, geography, and genetics. Annu Rev Ecol Evol Syst, 40:637-656

9. Smith SD: Using phylogenetics to detect pollinator-mediated floral evolution. New Phytol 2010, 188(2):354-363

10. Ollerton J, Winfree $\mathrm{R}$, Tarrant S: How many flowering plants are pollinated by animals? Oikos 2011, 120(3):321-326.

11. Gegear RJ, Burns JG: The birds, the bees, and the virtual flowers: can pollinator behavior drive ecological speciation in flowering plants? Am Nat 2007, 170(4):551-566.

12. Fenster CB, Armbruster WS, Wilson P, Dudash MR, Thomson JD: Pollination syndromes and floral specialization. Annu Rev Ecol Evol Syst 2004, 35(1):375-403.

13. Proctor M, Yeo P, Lack A: The Natural History of Pollination. London: Harper Collins Publishers; 1996.

14. Peitsch D, Fietz A, Hertel H, Desouza J, Ventura DF, Menzel R: The spectral input systems of hymenopteran insects and their receptor-based colorvision. J Comp Physiol A 1992, 170(1):23-40.

15. Briscoe AD, Chittka L: The evolution of color vision in insects. Annu Rev Entomol 2001, 46:471-510.

16. Gross CL: Floral traits and pollinator constancy: foraging by native bees among three sympatric legumes. Aust J Ecol 1992, 17:67-74.

17. Cresswell JE: Stabilizing selection and the structural variability of flowers within species. Ann Bot 1998, 81(4):463-473.

18. Whittall JB, Hodges SA: Pollinator shifts drive increasingly long nectar spurs in columbine flowers. Nature 2007, 447(7145):706-712

19. Thomson JD, Wilson P: Explaining evolutionary shifts between bee and hummingbird pollination: convergence, divergence, and directionality. Int J Plant Sci 2008, 169(1):23-38.

20. Tripp EA, Manos PS: Is floral specialization an evolutionary dead-end? Pollination system transitions in Ruellia (Acanthaceae). Evolution 2008, 62(7):1712-1737.

21. Schemske DW, Bradshaw HD: Pollinator preference and the evolution of floral traits in monkeyflowers (Mimulus). Proc Natl Acad Sci USA 1999, 96(21):11910-11915

22. Brown EM, Burbidge AH, Dell J, Edinger D, Hopper SD, Wills RT: Pollination in Western Australia: A Database of Animals Visiting Flowers. Perth: Western Australian Naturalists' Club; 1997.

23. Hingston $A B, M c$ Quillan PB: Are pollination syndromes useful predictors of floral visitors in Tasmania? Austral Ecol 2000, 25(6):600-609.

24. Keighery GJ: Bird pollination in south Western Australia - a checklist. Plant Syst Evol 1980, 135(3-4):171-176.

25. Keighery GJ: Bird-Pollinated Plants in Western Australia. In Pollination and Evolution. Edited by Armstrong JA, Powell JM, Richards AJ. Sydney: Royal Botanic Gardens; 1982:77-89.

26. Keighery GJ: Pollination of Jansonia formosa Kipp. ex Lindl. (Papilionaceae) West Aust Nat 1984, 16:21

27. Crisp MD: Evolution of bird-pollination in some Australian legumes (Fabaceae). Linn Soc Symp Ser 1994, 17:281-309.

28. Crisp MD: Convergent Evolution of Bird Pollination in Western Australian Fabaceae and its Taxonomic Implications. In Gondwanan Heritage: Past, Present and Future of the Western Australian Biota. Edited by Hopper SD,
Chappill JA, Harvey MS, George AS. Chipping Norton, NSW: Surrey Beatty \& Sons; 1996:179-186.

29. Wojciechowski MF, Lavin M, Sanderson MJ: A phylogeny of legumes (Leguminosae) based on analysis of the plastid matKgene resolves many well-supported subclades within the family. Am J Bot 2004, 91:1846-1862.

30. Crisp MD, Cook LG: Explosive radiation or cryptic mass extinction? Interpreting signatures in molecular phylogenies. Evolution 2009, 63(9):2257-2265.

31. Rambaut A: Se-Al: Sequence Alignment Editor. University of Oxford, Department of Zoology; 1996. Available at http://tree.bio.ed.ac.uk/

32. Zwickl DJ: Genetic Algorithm Approaches for the Phylogenetic Analysis Large Biological Sequence Datasets Under the Maximum Likelihood Criterion. Dissertation: Ph.D; 2006

33. Ronquist F, Huelsenbeck JP: MrBayes 3: Bayesian phylogenetic inference under mixed models. Bioinformatics 2003, 19(12):1572-1574.

34. Sanderson MJ: r8s: inferring absolute rates of molecular evolution and divergence times in the absence of a molecular clock. Bioinformatics 2003, 19(2):301-302.

35. Maddison WP, Maddison DR: Mesquite: a modular system for evolutionary analysis. 2010: Version 2.73 http://mesquiteproject.org

36. Dollo L: Les lois de l'évolution. Bulletin de la Société Belge de Géologie de Paléontologie et d'Hydrologie 1893, 7:164-166.

37. Gould SJ: Dollo on Dollo's Law: irreversibility and the status of evolutionary laws. J Hist Biol 1970, 3(2):189-212.

38. Maddison WP, Midford PE, Otto SP: Estimating a binary character's effect on speciation and extinction. Syst Bio/ 2007, 56(5):701-710.

39. Goldberg EE, lgic B: On phylogenetic tests of irreversible evolution. Evolution 2008, 62(11):2727-2741.

40. Burnham KP: Multimodel inference: understanding AIC and BIC in model selection. Sociol Methods Res 2004, 33(2):261-304.

41. Crisp M, Cook L, Steane D: Radiation of the Australian flora: what can comparisons of moelcular pylogenies across multiple taxa tell us about the evolution of diversity in present-day communities? Philos Trans $R$ Soc Lond 2004, 359:1551-1571.

42. Schodde R: Origins, radiations and sifting in the Australasian biota: changing concepts from new data and old. Aust Sysematics Bot Soc News/ 1989, 60:2-11

43. Lavin M, Herendeen PS, Wojciechowski MF: Evolutionary rates analysis of Leguminosae implicates a rapid diversification of lineages during the tertiary. Syst Biol 2005, 54(4):575-594.

44. Arroyo M: Breeding Systems and Pollination Biology in Leguminosae. In Advances in Legume Systematics Part 2. Edited by Polhill R, Raven P. Kew: Royal Botanic Gardens; 1981:723-769.

45. Joseph L, Toon A, Nyári ÁS, Longmore NW, Rowe KMC, Haryoko T, Trueman J, Gardner JL: A new synthesis of the molecular systematics and biogeography of honeyeaters (Passeriformes: Meliphagidae) highlights biogeographical complexity of a spectacular avian radiation. Zoologica Scripta 2014. doi:10.1111/zsc.12049

46. Schwarz MP, Fuller S, Tierney SM, Cooper SJB: Molecular phylogenetics of the exoneurine allodapine bees reveal an ancient and puzzling dispersal from Africa to Australia. Syst Biol 2006, 55(1):31-45.

47. Almeida EAB, Pie MR, Brady SG, Danforth BN: Biogeography and diversification of colletid bees (Hymenoptera: Colletidae): emerging patterns from the southern end of the world. J Biogeogr 2012, 39(3):526-544

48. Ödeen $\mathrm{A}$, Håstad O: Pollinating birds differ in spectral sensitivity. J Comp Physiol A 2010, 196:91-96.

49. Barker NP, Weston PH, Rutschmann F, Sauquet H: Molecular dating of the 'Gondwanan' plant family Proteaceae is only partially congruent with the timing of the break-up of Gondwana. J Biogeogr 2007, 34(12):2012-2027.

50. Shrestha M, Dyer AG, Boyd-Gerny S, Wong BBM, Burd M: Shades of red: bird-pollinated flowers target the specific colour discrimination abilities of avian vision. New Phytol 2013, 198(1):301-310.

51. Jesson LK: Ecological correlates of diversification in New Zealand angiosperm lineages. N Z J Bot 2007, 45(1):35-51.

52. Smith S, Miller R, Otto S, Fitzlohn R, Rausher M: The Effects of Flower Color Transitions on Diversification Rates in Morning Glories (Ipomoea Subg. Quamoclit, Convolvulaceae). In Darwin's Heritage Today: Proceedings of the Darwin 2000 Beijing International Conference. Edited by Long M, Gu H, Zhou Z. Beijing: Higher Education Press; 2010 
53. Futuyma DJ, Moreno G: The evolution of ecological specialization. Annu Rev Ecol Syst 1988, 19:207-233.

54. Hughes M, Moller M, Edwards TJ, Bellstedt DU, Villiers M: The impact of pollination syndrome and habitat on gene flow: a comparative study of two Streptocarpus (Gesneriaceae) species. Am J Bot 2007, 94(10):1688-1695.

55. Kramer AT, Fant JB, Ashley MV: Influences of landscape and pollinators on population genetic structure: examples from three penstemon (Plantaginaceae) species in the great basin. Am J Bot 2011, 98(1):109-121.

56. Byrne $\mathrm{M}$, Elliott CP, Yates $C$, Coates DJ: Extensive pollen dispersal in a birdpollinated shrub, Calothamnus quadrifidus, in a fragmented landscape. Mol Ecol 2007, 16(6):1303-1314.

57. Krauss SL, He T, Barrett LG, Lamont BB, Enright NJ, Miller BP, Hanley ME: Contrasting impacts of pollen and seed dispersal on spatial genetic structure in the bird-pollinated Banksia hookeriana. Heredity 2009, 102(3):274-285.

58. Ottewell KM, Donnellan SC, Lowe AJ, Paton DC: Predicting reproductive success of insect- versus bird-pollinated scattered trees in agricultural landscapes. Biol Conserv 2009, 142(4):888-898.

59. Cook LG, Crisp MD: Directional asymmetry of long-distance dispersal and colonization could mislead reconstructions of biogeography. $J$ Biogeogr 2005, 32(5):741-754

60. Galis F, Arntzen JW, Lande R: Dollo's Law and the irreversibility of digit loss in Bachia. Evolution 2010, 64(8):2466-2476.

61. Cronk QCB: Evolution in reverse gear: the molecular basis of loss and reversal. Cold Spring Harbor Symp Quant Biol 2009, 74:259-266.

62. Orians GH, Milewski AV: Ecology of Australia: the effects of nutrient-poor soils and intense fires. Biol Rev 2007, 82(3):393-423.

63. Ford $\mathrm{HA}$, Paton DC, Forde N: Birds as pollinators of Australian plants. N Z J Bot 1979, 17(4):509-519.

64. Pyke GH: The foraging behavior of Australian honeyeaters - a review and some comparisons with hummingbirds. Aust J Ecol 1980, 5(4):343-369.

65. He TH, Lamont BB, Krauss SL, Enright NJ, Miller BP: Covariation between intraspecific genetic diversity and species diversity within a plant functional group. J Ecol 2008, 96(5):956-961.

doi:10.1186/1471-2148-14-43

Cite this article as: Toon et al.: Evolutionary consequences of shifts to bird-pollination in the Australian pea-flowered legumes (Mirbelieae and Bossiaeeae). BMC Evolutionary Biology 2014 14:43.

\section{Submit your next manuscript to BioMed Central and take full advantage of:}

- Convenient online submission

- Thorough peer review

- No space constraints or color figure charges

- Immediate publication on acceptance

- Inclusion in PubMed, CAS, Scopus and Google Scholar

- Research which is freely available for redistribution
C Biomed Central 